\title{
Model for Improvement of Fluxing Process on Selective Soldering Machines (model 6747)
}

\author{
Goran TASEVSKI \\ Visteon Electronics, Skopje, Republic of Macedonia \\ gtasevsk@visteon.com \\ Elena PAPAZOSKA \\ Visteon Electronics, Skopje, Republic of Macedonia \\ ebachano@visteon.com
}

\begin{abstract}
Selective soldering is the process of soldering components to printed circuit boards that could not be treated in a reflow oven in a traditional surface-mount technology process due to thermal shock and damaging. Process of flux appliance as a first step of the selective soldering process sets the baseline for achieving high quality and robustness of the soldered joints.

Purpose of this research is to identify the factors that directly influence the effectiveness of the fluxing process in selective soldering machines, using the design of experiment methodology with associated factors and levels used in the experiment. Final findings gives directions for set up of the optimal fluxing parameters that will enable appropriate flux appliance and to gain reduction of soldering quality issues which foundations are from this process.
\end{abstract}

Keywords: selective soldering, fluxing, quality, improvement

\section{INTRODUCTION}

The first demand for selective soldering is that the parts to be soldered are clean. Therefore is requirement for flux application on all components that need to be soldered. Often it is difficult to prove if the flux did penetrate sufficiently in capillaries between hole and lead. Especially if those holes are covered on the topside of the PCB by the component body.

The most common used flux-application-process for the multi wave-soldering is to use drop-jet fluxer. This type of fluxer makes application of small flux-drops with using of $\mathrm{x} / \mathrm{y}$ axis-system. Technical characteristics of the drop jet fluxer are: 
- The drop jet is a small nozzle with a Piezo-element,

- $\quad$ The size of the nozzle is $1001 \mathrm{Jm}, 1301 \mathrm{Jm}$ or $2701 \mathrm{Jm}$.

- $\quad$ The most used nozzle-size is $130 \mathrm{IJm}$.

- The drop jets are mounted on a X-N-axis-system,

- The machine could have 1 or 2 drop jets,

- $\quad$ The $\mathrm{Z}$ axis is fixed.

- For each solder-joint the X-N-position, the drop-size and the number of dots can be programmed,

- For a row of solder-joints (for example connectors) it is possible to dispense a row of flux,

- Additional parameter for the amount of flux is here the axis-speed.

- The flux-application is done by opening the drop jet - nozzle with a defined openingtime and frequency. With the opening-time the drop-size can be influenced.

- $\quad$ Using the frequency the number of dots per time can be influenced.

- The flux is stored in a pressure-tank with a low pressure of 0,3 bar, with which the flux is pressed to the drop jet - nozzles. When the pressure of the flux-system is too high, the risk is to have flux splashes on the PCB outside the defined area.

- The flux-head shoot very small flux-dots onto the Bottom-side of the PCB at the programmed position. It is a selective fluxer.

- The amount of flux is programmable separately for each solder-joint.

- The machine must have a zero-position or a procedure to ensure a good indexing of the PCB.

- The nozzle of the flux-unit must be clean to get a homogeneous flux area on the board.

- The cleaning of the nozzle is done by using isopropyl - alcohol and a soft tissue.

- In case of too much flux, there are risks to have micro balls, pollution of PCB, components and carrier,

- In case of too low flux, we have bad wetting, bad through-hole-filling and residues from the solder process.

Parameters that need to be controlled:

- Drop-size (opening time),

- Frequency (number of drops per second),

- Axis-speed for lines,

- Calibration of axis-position (X,Y),

- Cleanliness of drop jet,

- Flux location and uniformity - visually check in the beginning of the shift and after change-over,

- Flux-area (quantity),

- $\quad$ Pressure in the flux-tank.

\section{PROBLEM STATEMENT AND PROJECT OBJECTIVE}

Problem statement for the research was a case study from SMD manufacturing plant. Problem was stated as a: excessive flux on test points around the connector of NCV 
product, see figure 1. Due to this issue all affected produced pcbs fail on the final station, Functional Tester with "Wrong Pin Check" defect reported.

Flux on the test points comes from Wave soldering machine - (Before FCT testing all affected pcbs pass wave soldering process - soldering of connector, stepper motors and relay components).
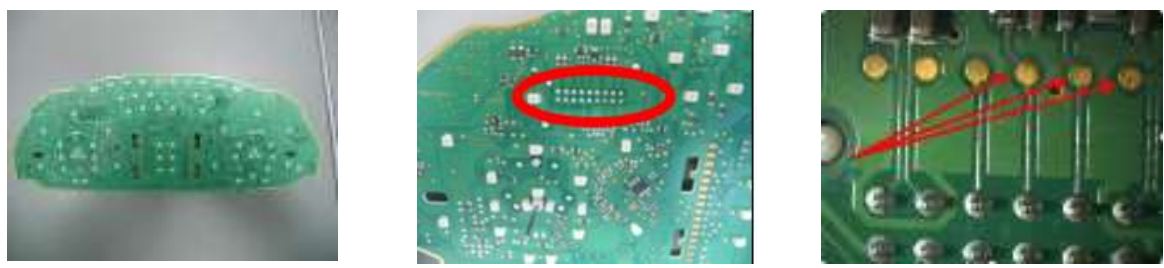

\section{Figure 1: Printed circuit board with flux affected test point around connector area.}

Project objective: Improve process of fluxing on wave soldering machine (model 6747). Target is to optimise main factors and appropriate levels of drop jet flux parameters due to achieve quality of the solder joints on wave soldered components and avoid flux appliance on test components around connector area, figure 2 :

\section{INITIAL PROCESS FLOW}
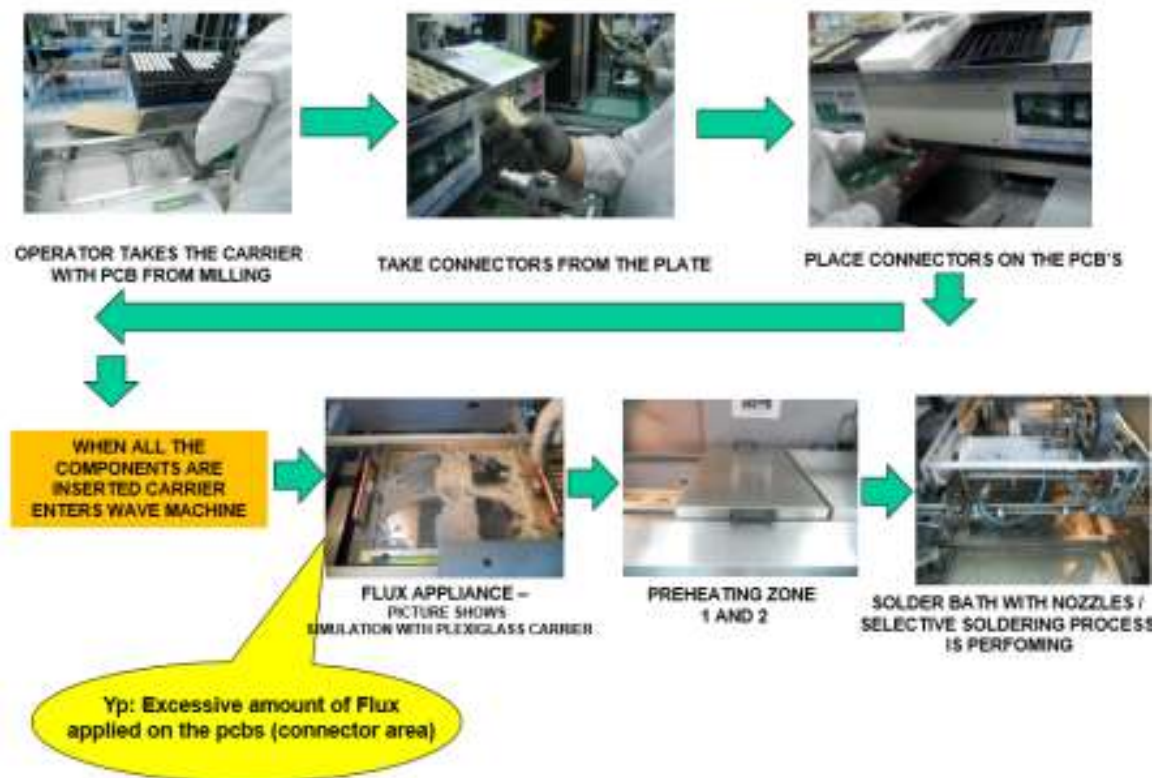

Figure 2: Initial process flow of wave soldering process (With highlighted fluxing process issue area) 


\section{DESIGN OF EXPERIMENT}

Objective of the design of experiment was to consistently achieve a desired level of flux, with no test points affected and solder joint not to be weak.

Output measure is application of flux - not to exceed $5 \mathrm{~mm}$ from reception area on the pcb (where flux needs to be applied).

\begin{tabular}{|l|cc|}
\hline Factors Tested in Experiment & \multicolumn{1}{|c|}{ Levels } & 1 \\
\cline { 2 - 3 } A. Speed of Drop Jet Movement. & 20 & 30 \\
B. Drop Size of flux applied. & $1.3 \mathrm{~ms}$ & $1.5 \mathrm{~ms}$ \\
C. Frequency of flux application & $100 \mathrm{~Hz}$ & $130 \mathrm{~Hz}$ \\
\hline
\end{tabular}

\section{Figure 3: Factors and their levels tested in the experiment}

X's verified through DOE, see Figure 3:

Factor A = Drop Jet speed,

Factor $\mathrm{B}=$ Flux drop size $(\mathrm{mS})$,

Factor $\mathrm{C}=$ Frequency of flux application.

Using the assigned factors and levels, experiment was performed on 24 printed circuit boards using eight different combination of factors and levels, and this eight different combination was repeated three times. Table 1 below shows the design of experiment and achieved values:

Table 1: Design of Experiment guideline

\begin{tabular}{|c|c|c|c|c|c|c|c|c|}
\hline \multicolumn{3}{|c|}{ Combination } & \multicolumn{3}{|c|}{ Factors } & \multirow{2}{*}{$\begin{array}{c}\text { Pcb No. } \\
1 \\
\end{array}$} & \multirow{2}{*}{$\begin{array}{l}\text { Left } \\
6,165 \\
\end{array}$} & \multirow{2}{*}{$\begin{array}{l}\text { Right } \\
6,334\end{array}$} \\
\hline-1 & -1 & -1 & 30 & $1.3 \mathrm{~ms}$ & $130 \mathrm{~Hz}$ & & & \\
\hline 1 & -1 & -1 & 20 & $1.3 \mathrm{~ms}$ & $130 \mathrm{~Hz}$ & 2 & 5,491 & 5,311 \\
\hline-1 & 1 & -1 & 30 & $1.5 \mathrm{~ms}$ & $130 \mathrm{~Hz}$ & 3 & 3,164 & 4,234 \\
\hline 1 & 1 & -1 & 20 & $1.5 \mathrm{~ms}$ & $130 \mathrm{~Hz}$ & 4 & 6,102 & 5,457 \\
\hline-1 & -1 & 1 & 30 & $1.3 \mathrm{~ms}$ & $100 \mathrm{~Hz}$ & 5 & 3,302 & 4,442 \\
\hline 1 & -1 & 1 & 20 & $1.3 \mathrm{~ms}$ & $100 \mathrm{~Hz}$ & 6 & 5,442 & 5,008 \\
\hline-1 & 1 & 1 & 30 & $1.5 \mathrm{~ms}$ & $100 \mathrm{~Hz}$ & 7 & 5,684 & 3,175 \\
\hline 1 & 1 & 1 & 20 & $1.5 \mathrm{~ms}$ & $100 \mathrm{HZ}$ & 8 & 5,379 & 4,818 \\
\hline-1 & -1 & -1 & 30 & $1.3 \mathrm{~ms}$ & $130 \mathrm{~Hz}$ & 9 & 5,474 & 5,581 \\
\hline 1 & -1 & -1 & 20 & $1.3 \mathrm{~ms}$ & $130 \mathrm{~Hz}$ & 10 & 5,25 & 5,997 \\
\hline-1 & 1 & -1 & 30 & $1.5 \mathrm{~ms}$ & $130 \mathrm{~Hz}$ & 11 & 4,513 & 4,929 \\
\hline 1 & 1 & -1 & 20 & $1.5 \mathrm{~ms}$ & $130 \mathrm{~Hz}$ & 12 & 4,831 & 4,283 \\
\hline-1 & -1 & 1 & 30 & $1.3 \mathrm{~ms}$ & $100 \mathrm{~Hz}$ & 13 & 5,062 & 5,062 \\
\hline 1 & -1 & 1 & 20 & $1.3 \mathrm{~ms}$ & $100 \mathrm{~Hz}$ & 14 & 5,063 & 5,366 \\
\hline-1 & 1 & 1 & 30 & $1.5 \mathrm{~ms}$ & $100 \mathrm{~Hz}$ & 15 & 5,176 & 3,057 \\
\hline 1 & 1 & 1 & 20 & $1.5 \mathrm{~ms}$ & $100 \mathrm{HZ}$ & 16 & 5,199 & 4,675 \\
\hline-1 & -1 & -1 & 30 & $1.3 \mathrm{~ms}$ & $130 \mathrm{~Hz}$ & 17 & 5,239 & 5,413 \\
\hline 1 & -1 & -1 & 20 & $1.3 \mathrm{~ms}$ & $130 \mathrm{~Hz}$ & 18 & 5,32 & 4,594 \\
\hline-1 & 1 & -1 & 30 & $1.5 \mathrm{~ms}$ & $130 \mathrm{~Hz}$ & 19 & 4,224 & 4,76 \\
\hline 1 & 1 & -1 & 20 & $1.5 \mathrm{~ms}$ & $130 \mathrm{~Hz}$ & 20 & 5,245 & 5,028 \\
\hline-1 & -1 & 1 & 30 & $1.3 \mathrm{~ms}$ & $100 \mathrm{~Hz}$ & 21 & 5,148 & 5,423 \\
\hline 1 & -1 & 1 & 20 & $1.3 \mathrm{~ms}$ & $100 \mathrm{~Hz}$ & 22 & 5,076 & 5,278 \\
\hline-1 & 1 & 1 & 30 & $1.5 \mathrm{~ms}$ & $100 \mathrm{~Hz}$ & 23 & 5,306 & 5,829 \\
\hline 1 & 1 & 1 & 20 & $1.5 \mathrm{~ms}$ & $100 \mathrm{HZ}$ & 24 & 5,076 & 4,03 \\
\hline
\end{tabular}




\section{EXPERIMENT RESULTS}

Achieved results from the experiment were processed in Minitab, to provide statistical evidence of the most influenced factors to the process variation.

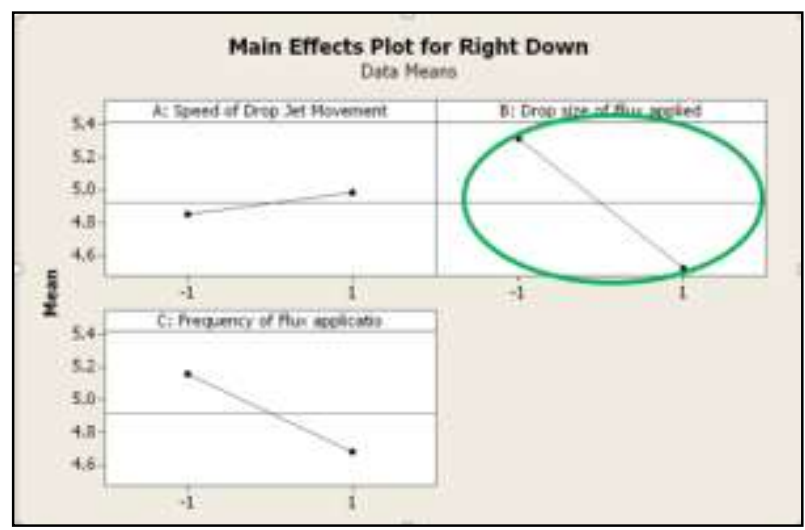

Figure 4: Main effect plot from the experiment

According the plot analyze shown on the picture, factors A and B interact differently in two cases. This gives direction to lower standard deviation of the process as a part of the improve phase. Target of the design of experiment is to lower standard deviation because in some case we have area affected with flux $6 \mathrm{~mm}$ (upper limit is $5 \mathrm{~mm}$ ) and in some nominal value is $3,5 \mathrm{~mm}$. According this we do not need to shift mean of the process because it did not affect the measurement.

For standard deviation to be on the lowest value, factors and levels should be:

$\mathrm{A}(1)=30$,

$\mathrm{B}(-1)=1.3 \mathrm{mS}$,

$\mathrm{C}(1)=130 \mathrm{~Hz}$.

After implementation of this parameters, capability of the fluxing process was performed. We use 40 pcbs produced in different shift, and we measure flux appliance, test point around connector affection with flux and quality of the solder joint. From the chart below (Figure 5) we can see that capability factor $\mathrm{Cpk}=1,01$ which is acceptable (>1.00). Decreased PPM of overall performance $=641.67$. Process is capable. Which gives us direction forward to strive to continuously improve the process to achieve desired level of $\mathrm{Cpk}=1,69$. 


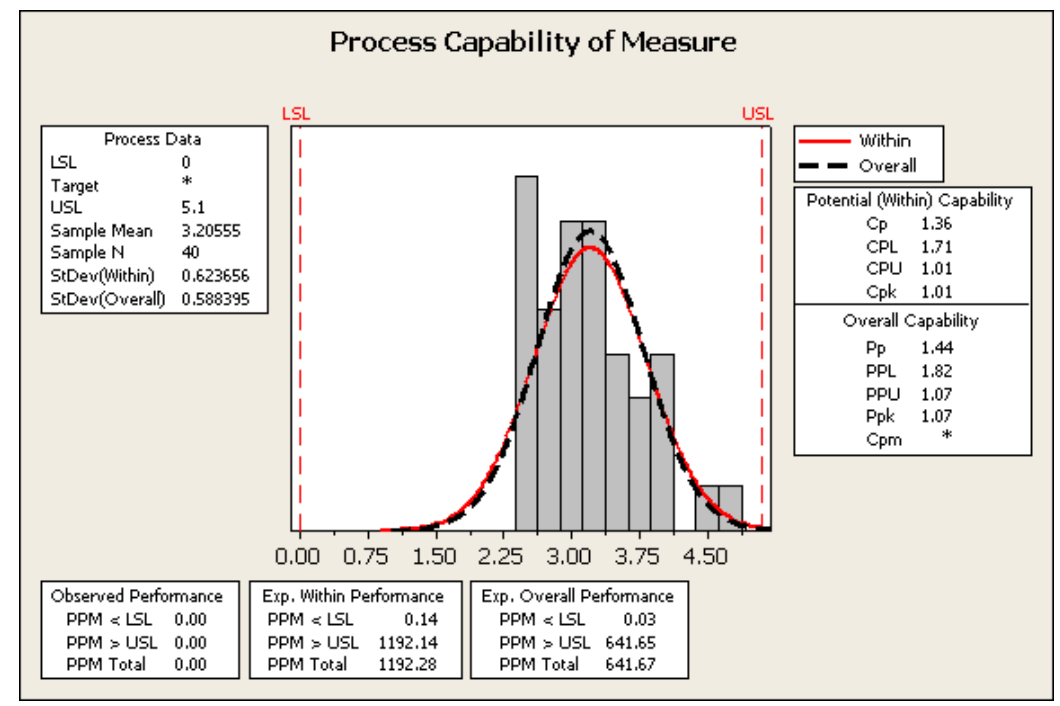

Figure 5: Capability of the fluxing process after implementation of new solution

\section{CONCLUSION}

Purpose of the flux in the wave soldering process has a primary and a secondary objective. The primary objective is to clean the components that are to be soldered, mainly any oxide layers that may have formed. Importance of the proper flux appliance is mandatory as a first step in the selective soldering process. Optimized settings of the main parameters and their levels for the flux drop jet is recommended considering the first requirement from the process: quality of the solder joint and the second requirement which is avoidance of flux application on the other components and test points around the solder area. Achieved optimized parameters and their correlation as a result of this experiment gives solid baseline for stable process set up with acceptable capability of process performance during time. As a further directions for research is optimization of a process when two drop jets are used in same machine and avoidance of constraints that appear when set up is done on all appropriate factors.

\section{REFERENCES}

Tasevski G. (2012). Black Belt certification project. Skopje, Republic of Macedonia.

Vitronics Soltec. (2015) Fluxer tips and tricks. Retrieved November 15, 2012, from http://www.vitronics-soltec.com/support/brochures/

Vitronics Soltec. (2015) mySelective 6747. Retrieved May 15, 2015, from http://www.vitronics-soltec.com/support/brochures/ 